istry and neuropharmacology of psychiatric disorder and suicide.

MRC Brain Metabolism Unit,

Royal Edinburgh Hospital,

Edinburgh EH10 5HF

\footnotetext{
1 Muldoon MF, Manuck SB, Matthews KA, Owen NG. Cholesterol concentration and mortality: a quantitative review of primary prevention trials. $B M f^{1}$ 1990;301:309-14.

Law MR, Thompson SG, Wald NJ. Assessing possible hazards of reducing serum cholesterol. BMf 1994;308:373-9.

3 Engelberg H. Low serum cholesterol and suicide. Lancet 1992;339:727-9.

4 Oliver MF. Might treatment of hypercholesterolaemia increase non-cardiac mortality? Lancet
} 1991;337:1529-31.
Lindberg G, Rastam L, Gullberg B, Eklund GA. Low serum cholesterol concentration and short term mortality from injuries in men and women. BMf 1992;305:277-9.

Vartiainen E, Puska P, Pekkanen J, Tuomilehto J, Lonnqvist J, Ehnholm C. Serum cholestero and accidental or other violent deaths. $B M F$ 1994;309:445-7.

7 Chen Z, Peto R, Collins R, MacMahon S, Lu J, Li W. Serum cholesterol concentration and coronary heart disease in population with low cholesterol concentrations. $B M f$ 1991;303:276-82.

8 Warr P, Jackson P. Factors influencing psychological impact of prolonged unemployment and reemployment. Psychol Med 1985;15:795-807.

veemployment. Psychol Med 1985;15:795-807.

9 Virrkunen M. Serum cholesterol in antisocial personality. Neuropsychobiology 1979;5:27-30. triglycerides and aggression in the general population. Lancet 1992;340:995-8.

1 Brunner E, Davey Smith G, Pilorim J, Marmot M. Low serum cholesterol and suicide. Lance 1992;339:1001-2.

12 Morgan R, Palinkas L, Barrett Connor E, Wingard D. Plasma cholesterol and depressive symptoms in older men. Lancet 1993;341:75-9.

13 Lori Brown S, Salive ME, Harris TB, Simonsick EM, Guralnik JM, Kohout FJ. Low cholesterol concentrations and severe depressive symptoms in elderly people. $B M F$ 1994;308:1328-32.

14 Miles CP. Conditions predisposing to suicide-a review. $\mathcal{F}$ Nerv Ment Dis 1977;164:231

\title{
Innovation in the pharmaceutical industry
}

\section{Partnerships with outside organisations will become imperative}

The pharmaceutical industry today is operating in an environment whose main feature is an unprecedented pace of change. In most markets the rising costs of health care are of increasing concern, and the medicines bill is being targeted for savings. New constraints are limiting the medicines that can be used and paid for in the system. In the United States health maintenance organisations use formularies, while European governments are resorting to various measures to control the pricing and prescribing of medicines and are increasing the range of medicines available over the counter. Medical practice is also changing for demographic reasons, and the health problems of elderly people are attracting increasing attention.

Drug regulation is both costly and time consuming, particularly in the clinical phases. Now, in addition to the stringent demands for safety and efficacy, the need to show the economic benefits of a new medicine is increasingly emphasised. Although these changes may well sink some pharmaceutical companies, they should be seen as challenges to be met to ensure the future of both the industry and the communities who benefit from its activities. Undoubtedly, the pharmaceutical industry's future success will depend on innovative medicines that meet unmet clinical needs and provide genuine therapeutic advance.

Fortunately, other rapid changes may work in the industry's favour. Advances in biotechnology and the biomedical sciences in particular are providing opportunities to discover medicines that can be targeted at disease processes with a degree of precision rarely possible before. This holds out the prospect of medicines that cure rather than palliate diseases. To make best use of these opportunities, however, the industry must change its approach to discovering drugs.

The "traditional" approach has undoubtedly been successful and provided such important classes of medicines as $\mathrm{B}$ blockers, $\mathrm{H}_{2}$ antagonists, non-steroidal anti-inflammatory drugs, and antibiotics. Essentially, this approach is based on a knowledge of physiological processes, such as the effects of adrenaline on blood vessels, and of biochemical pathways for molecules suspected of having a role in disease processes, such as the prostanoids. The discovery of medicines has primarily depended on chemical modification of natural mediators or substrates and evaluation of the modified molecule to establish its action at the receptor or enzyme. In terms of the resources needed for discovering drugs the industry was largely self sufficient and not reliant to any great extent on research done outside the companies.

During the past two decades the explosion in biological knowledge, fuelled by the rapid development of molecular and cellular biology, has opened new approaches to the discovery of medicines. These approaches are biological rather than chemical. They put us in a better position to unravel the molecular and cellular processes underlying important chronic diseases and to identify key molecules in pathways and cascades, providing targets for rational, and more precise, design and discovery of drugs. Although chronic diseases such as rheumatoid arthritis have so far defied attempts to find safe, curative medicines, these conditions may now be amenable to study with the tools provided by recombinant DNA technology, genome analysis, and non-invasive imaging techniques.

The advances being made in the understanding of cystic fibrosis are a good example of the power of these technologies to provide novel approaches to the treatment of disease. Biotechnology has shown us the molecular basis for the cellular defect in this condition and allowed the identification of the single mutant "culprit" gene and its defective gene product. ${ }^{1}$ This opens the way, theoretically, for the normal gene to be introduced into affected human lung cells to correct the deficiency, opening up the possibility of gene therapy. ${ }^{2}$ Clinical trials of gene therapy have started recently, ${ }^{3}$ with at least 50 protocols for genetic diseases, including cystic fibrosis; these should define the effectiveness and value of this approach. ${ }^{4}$

We must be careful, however, to recognise the limitations of gene therapy: although of likely value in monogenic diseases, it may be inappropriate in diseases with a polygenic basis - which includes many chronic diseases. New technologies are also, however, providing insights into the molecular processes underlying gene regulation, which may provide routes to the treatment or prevention of diseases in which several gene products may be interacting. Use of antisense molecules, for example, may provide "gene regulating" medicines for the future. ${ }^{56}$ The key to opening the door to these exciting possibilities lies in the sequencing of the human genome. The international activities in this field are expected to aid the 
discovery of drugs by identifying genes related to diseases and giving access to their molecular products.

These new approaches present the industry with new opportunities but challenge how it manages its research and development. Firstly, the range of technologies and skills required for this new way of discovering drugs makes a multidisciplinary approach essential. Clearly, pharmaceutical companies cannot be self sufficient in terms of the science and technology needed for success. They must look outside, to academic institutions and smaller biotechnology companies. The future must see the establishment of alliances and collaborations between the industry and these other sectors to harness new knowledge effectively. To get maximum benefit, however, these alliances must be real, well managed partnerships, with partners being committed at all levels and contributing their particular skills and resources. The partners must recognise and respect the particular contribution that each can make to the process of the creation, discovery, development, and marketing of new medicines. The risks and rewards of this collaboration must be genuinely shared.

Secondly, the new approach requires commitment to long term, focused research, with a clear mission to understand disease processes. The industry must therefore be prepared to invest substantial sums of money in research programmes in basic medical sciences in academic laboratories to ensure that relevant and vital studies related to disease are carried out. But it should not be alone in meeting this objective of enlarging our knowledge of disease-it must be partnered by the government, through the research councils and similar bodies. They too should be ready to provide substantial funding for major programmes of strategic importanceboth to the industry and, more particularly, to the provision of better health care in the future.

RICHARD SYKES Chief executive

Glaxo Holdings,

London W1X 6BQ

1 Rommens MJ, Iannuzzi MC, Kerem B-S, Drumm ML, Melmer G, Dean M, et al. Identification of the cystic fibrosis gene; chromosome walking and jumping. Science 1989;245:1059-65.

2 Hyde SC, Gill DR, Higgins CF, Trezise AE, MacVinish LJ, Cuthbert AW, et al. Correction of the ion transport defect in cystic fibrosis transgenic mice by gene therapy. Nature 1993;362:250-5.

3 Davies K, Williamson B. Gene therapy begins. BMF 1993;306:1625-6.

4 Anderson WF. Human gene therapy. Science 1992;256:808-13.

5 Simons M, Edelman ER, DeKeyser J-L, Langer R, Rosenberg RD. Antisense c-myb oligonucleotides inhibit intimal arterial smooth muscle cell accumulation in vivo. Nature 1992;357:67-70.

6 Morishita R, Gibbons GH, Ellison EK, Nakajima M, von der Leyen H, Zhang L, et al. Intimal hyperplasia after vascular injury is inhibited by antisense cdk 2 kinase oligonucleotides. $\mathcal{F}$ Clin Invest 1994;93:1458-64.

\section{High security for mentally disordered people}

\section{A new report recommends that small units should be built}

Two years after the trenchant criticism of Ashworth Hospital by a committee of inquiry chaired by Sir Louis Blom-Cooper, QC, ${ }^{12}$ the Department of Health has published its review of high security and related psychiatric provision. Dr John Reed, senior principal medical officer, and his committee recommend sweeping changes in the way treatment under special security is provided for patients in England and Wales. ${ }^{34}$

High security provision is a new term which should encourage us to think of services rather than institutions. The report accepts that such provision will always have a place in the range of psychiatric services but that a service based on the three existing special hospitals (Ashworth in Merseyside, Broadmoor in Berkshire, and Rampton in Nottinghamshire) administered from a special health authority in London cannot continue. What is needed is something "generally more attuned to the wider delivery of mental health care on the eve of the twenty first century."

At present there are about 1700 patients in the special hospitals, two thirds of whom are subject to the authority of the home secretary. Sixteen per cent are women and $17 \%$ are from ethnic minorities. The population is far from static; 200 patients are admitted and discharged each year. More than half the patients suffer from schizophrenia, $25 \%$ are detained within the legal category psychopathic disorder, and $9 \%$ have a learning disability. One in seven are not offenders-they have been transferred from other hospitals. Half the current population may not even need treatment in conditions of high security, says the report. Indeed, more than 100 patients, including six who have been waiting for more than three years, are awaiting transfer to a local facility.
The report recommends that purchasing agencies should ensure that no patient waits longer than six months and that the backlog of 63 delayed transfers should be cleared urgently. It goes on to say that high security care is for mentally disordered patients who present a serious danger, usually to others, and who cannot be managed at a lower level of security. This is an identifiable clinical criterion; and this criterion rather than the non-availability of alternative resources should be the factor that determines admission. Reed suggests the total provision of high security places should remain unchanged at present but that future planning should be based on an early assessment of need conducted on a multiagency basis.

The report recommends the development of units with a maximum size of 200 places. These should be located closer to the populations they will serve and on sites that encourage integration with other services. To the guiding principles established in the recent comprehensive review of services for mentally disordered offenders (also conducted by Reed), ${ }^{5}$ the new report adds the principle that services should have regard for the rights of patients as citizens - a poignant reminder of the dismal events unearthed at Ashworth Hospital. It recommends a service more diverse in its provision, more sensitive to issues of race and gender, and with a more positive approach to staffing. Crucially, the new service must be able to command public and professional confidence. It should function on the purchaser-provider model, says the report, though it acknowledges that services cannot be "left to the influences and pressures of the market without safeguards."

Existing special hospitals, reduced in size, should become trusts, as should the proposed new high security units; they might benefit from integration within existing 